\title{
The composition of chrysanthemum extracts and their pharmacological functions
}

\author{
Wan-Li LIANG ${ }^{1,2}$, Dan GONG ${ }^{1,2}$, Wei Kevin ZHANG ${ }^{1,2}$ \\ ${ }^{1}$ Bioland Laboratory (Guangzhou Regenerative Medicine and Health Guangdong Laboratory), Guangzhou, 510700, China \\ ${ }^{2}$ School of Pharmaceutical sciences, South-Central University for Nationalities, Wuhan, 430064, China. \\ *Correspondence: wkzhang81@139.com \\ https://doi.org/10.37175/stemedicine.v2i5.69
}

\begin{abstract}
Chrysanthemum is a widely planted cash crop worldwide, due to its high ornamental and medicinal values. In addition, as a frequently used material in Traditional Chinese Medicine, studies have revealed that chrysanthemum extracts are complicated mixtures of flavonoids, volatile oils, organic acids, polysaccharides and other minor components, which possess pharmacological effects against many pathological conditions such as toxin-induced cell loss, bacterial infection-induced inflammation, reactive oxygen species-induced oxidative stress and tumor formation induced by various stimuli. In this mini review, we collected and summarized the current understanding on the composition and pharmacology of chrysanthemum extracts originally published in both Chinese and English, and aimed to broaden the readership, in order to build up the basis for eliciting more valuable investigations in this topic.
\end{abstract}

Keywords: Chrysanthemum extracts · Flavonoids · Volatile oils · Organic acids · Polysaccharides

\section{Introduction}

Being a leading valued flower worldwide, chrysanthemum is planted and studied due to its attractive appearance of colors and shapes (1), dynamic plant architectures, a variety of flowering times and post-harvest quality (2), and potential medicinal and therapeutic applications of its extracts (3). In addition, chrysanthemum has long been treated as an important medicinal substance with a wide usage in Traditional Chinese Medicine (TCM) (4-8). As documented in the classical literatures of TCM, which could date back to 1,000 B.C., the dried head-shaped flower sequence of chrysanthemum, with the Latin name of Dendranthema morifolium (Ramat.) Tzvel. possessed "sweet and bitter taste" ("taste" is usually referred to as the pharmacological characteristics of a certain medicine in TCM), and has the effects of dispersing "liver wind" (a TCM term indicating

Received: Nov 16, 2020; Accepted: Dec 16, 2020.

(c) The Author(s). 2020 This is an Open Access article distributed under the terms of the Creative Commons License (http://creativecommons.org/licenses/by/4.0/) which permits unrestricted use, distribution, and reproduction in any medium or format, provided the original work is properly cited. a range of health hazards in the liver that occur suddenly), balancing "liver and eyesight" (according to the theory of TCM, liver is highly correlated with eyes), clearing "heat" and detoxifying (9). Modern pharmacological studies have also suggested that chrysanthemum extracts possess cell protection $(10,11)$, anti-colitis, anti-tumor (12-14), anti-oxidation (15) and anti-bacterial effects (1619), as summarized in Figure 1. Moreover, the extracts of chrysanthemum have been shown to be capable of preventing lipid accumulation in the liver (20-22).

Modern Chinese literatures have demonstrated that the usefulness of chrysanthemum tea in alleviating symptoms such as headache, dizziness, thoracic fever, coronary heart disease and hypertension. According to the various origins and processing methods of the medicine, four varieties namely "Hang Ju", "Gong Ju", "Chu Ju" and "Bo Ju" have been suggested in the First Section of the Chinese Pharmacopoeia 2005 Edition. Additionally, other varieties of chrysanthemum are also seen in the market. Although some minor ingredients among varieties could be distinct, most of them include flavonoids (including apigenin, luteolin and quercetin), volatile oils (including mono- and sesquiterpene, their oxygen-containing derivatives and aromatic compounds), organic acids (such as chlorogenic 
acids), polysaccharides (composed of galactose, glucose, mannose and pectinose), and other minor components (vitamin $\mathrm{C}$, selenium, etc.) $(23,24)$. For a better illustration, the general composition and possible pharmacological effects of chrysanthemum extracts are summarized in Table 1. In this mini review, we collect and summarize the general components of chrysanthemum extracts and their pharmacological effects reported in Chinese literatures, as well as recent findings in English literatures, with the aim to build up the basis for more valuable investigations and avoid unnecessary redundant attempts for the separation of their composition and illustration of their pharmacological effects.

\section{Flavonoids in chrysanthemum extracts and their potential pharmacological effects}

\subsection{Types of flavonoids}

The flavonoids contained in chrysanthemums are mainly apigenin, luteolin, quercetin and their derivatives, such as flavonoid glycoside, flavonols and flavonol glycosides. Among these flavonoids, luteolin and quercetin are the most intensively studied, as summarized in Table 2.

\subsection{Pharmacological effects of flavonoids}

It has been reported that chrysanthemum total flavonoids possess inhibitory effect on oxidation induced by intensive lipid uptake and accumulation in a dose-dependent manner (25). This effect could be explained by the reduction of multiple phenol groups in flavonoids. Free radicals produced by the oxidation of lipids inside cells might react with these groups, and block the oxidation process due to these free radicals.

Total flavonoids of chrysanthemum could also reduce serum levels of triglyceride, total cholesterol, low-density lipoprotein cholesterol, non-esterified fatty acid in rats with lipid metabolism disorders (26). Meanwhile, they have been suggested to increase serum high-density lipoprotein cholesterol levels as well. Evidence combined together has shown that total flavonoids of chrysanthemum could serve as protective factors, which is capable of affecting the fat metabolism-related enzymes lipoprotein lipase and transport protein Apolipoprotein B, hence play an important role in the breakdown and transport of lipids. In histochemical studies, chrysanthemum flavonoids can reduce liver lesions caused by hyper-lipidism. It also has some effect on improving arterial vascular lesions caused by hyper-lipidemia. Wild chrysanthemum total flavonoids have been shown to inhibit the growth of fissicoccal yeast, staphylococcus, hemolytic staphylococcus, tropical candida, Staphylococcus aureus and malt-obsessed monocytobacteria, and thus possess the anti-microbial activity.

Studies have also shown that quercetin extracted from chrysanthemum could protect vascular endothelial cells (VECs) by promoting their proliferation. Certain doses of quercetin could inhibit hydrogen peroxide-induced release of the lactic acid dehydrogenase in VECs, promoting the secretion of precycline from the damaged VECs. As a result, quercetin is capable of keeping endothelial cells in the blood vessels intact and has the ability to resist oxidative damage (27). In addition, quercetin could reduce the expression of proliferating cell nuclear antigen (28), and thereby inhibit the activity of DNA polymerase by interfering with the synthesis of DNA, eventually suppressing the proliferation of tumor cells (29).

Meanwhile, luteolin extracted from chrysanthemum could significantly inhibit the extracellular regulation of protein kinase ERK2 (30), reduce ovarian cancer cell metastasis, thereby exerting an anti-cancer effect (31). Moreover, scholars have found that luteolin has a potent anti-inflammatory effect on bowel inflammation in rats (32). Meanwhile, reports have also implied that luteolin could inhibit the gene transcription of the pre-inflammatory factors in dendritic cells of the bone marrow (33). It has also been found that luteolin can effectively reduce the thickness of the airway wall and smooth muscle of asthma mice by inhibiting the secretion of pro-inflammatory cytokines such as interleukin (IL)-4 and IL-5, increasing the released level of interferon (INF)- $\gamma$, and thus improving the airway remodeling in asthma model mice (34).

Additionally, investigations with mouse ear swelling and vascular permeability experiments have shown that luteolin-7-O- $\beta$-D-glucosin, apigenin-7-O- $\beta$-Dglucosin and linarin, extracted and separated from wild chrysanthemum, have anti-inflammatory effects (35). In recent years, during the search for natural anti-viral compounds, crude extracts of chrysanthemum have been shown to inhibit human immunodeficiency virus (HIV)1 integrative enzyme. Further analysis has revealed that a type of apigenin glycoside, apigenin-7-O- $\beta$-D(4'-caffeoyl)-glucuronide, possesses the strongest antiHIV activity. A recent research has also indicated that monolith-clycosin-7-O-glucosin from chrysanthemum has an anti-hypertensive effect on blood pressure in rats (36).

\section{Volatile oils in chrysanthemum extracts and their potential pharmacological effects \\ 3.1 Types of volatile oils}

The volatile oil ingredients of chrysanthemum are mainly composed of monoterpenes and sesquiterpenes, their oxygen-containing derivatives, aromatic compounds and alkanes (37). Among them, the main components of monoterpenes include camphor, dragon brain, 1,8-aminoyl ether, $\alpha$-thujone, $\beta$-pinene, verbenone, verbenol and p-cymene. The main components of sesquiterpenes include farnesene, farnesol, zingiberene, bisabolol, cananga oil and $\alpha$-cadinol. Studies have shown that the distribution of the components of different varieties of volatile oils in chrysanthemums extracts is obviously different, and is related to the origin and processing methods. An analysis on the four major medicinal chrysanthemums, namely "Hang Ju", "Gong Ju", "Chu Ju" and "Bo Ju" has found that, the most volatile oil types are "Chu Ju", containing a total of 46 types of volatile oil composition, followed by "Bo Ju", which includes 35 varieties. "Gong Ju" and"Hang Ju" possess only 18 and 6 types of volatile oils, respectively. 


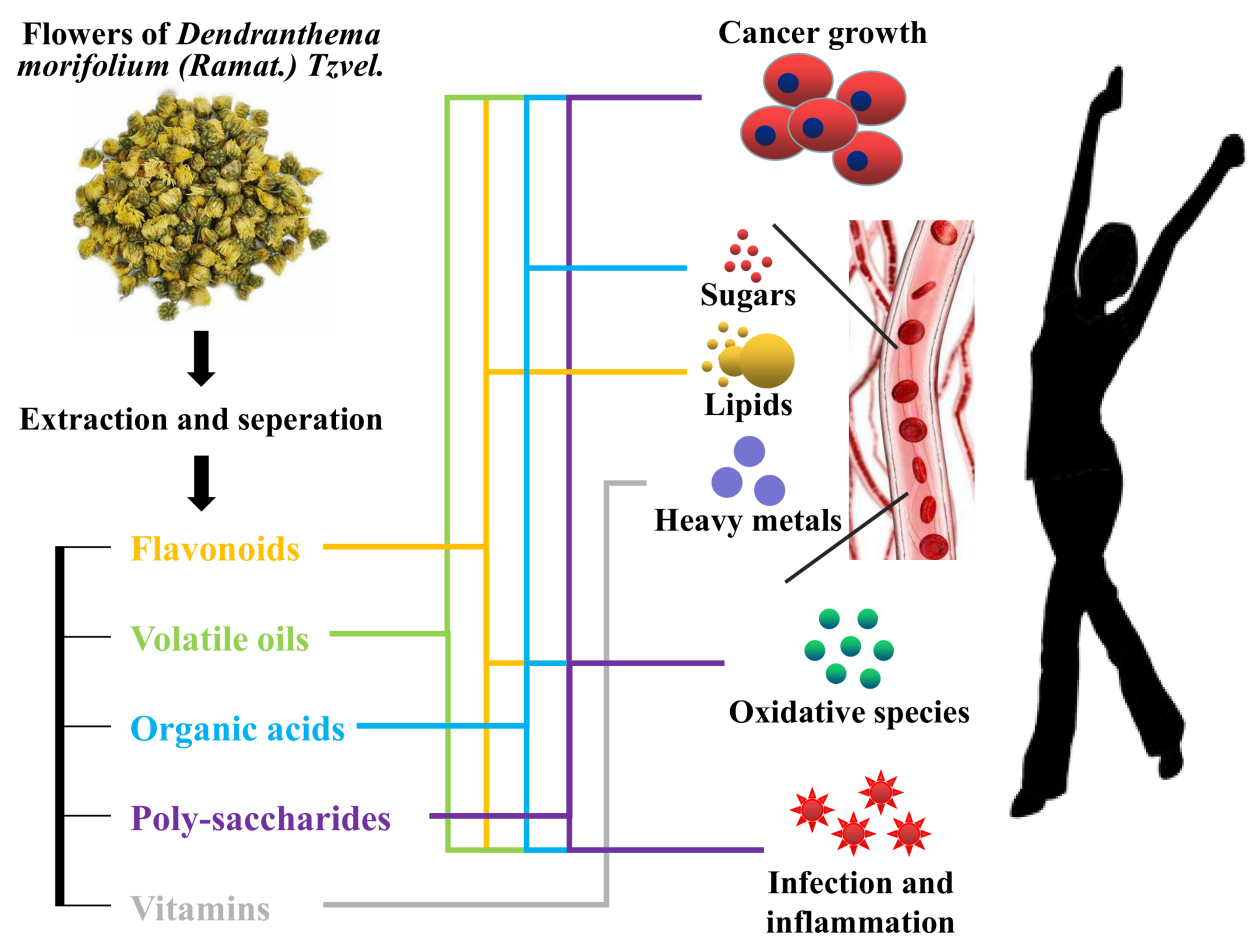

Figure 1. A summarization on the composition and possible pharmaceutical effects of Chrysanthemum extracts.

\subsection{Pharmacological effects of volatile oils}

In general, investigations have indicated that the volatile oil components of chrysanthemum have the ability of mutation suppression, anti-inflammation and anti-cancer effect (38), as summarized in Table 3.

In a study, the chrysanthemum volatile oil could inhibit sister-strand crossover induced by erythromycin and methylene sulfonate in mouse bone marrows. The authors have shown that the inhibitory effect might be exerted via reducing the split indies of sisterstrand monomer exchange induced by erythromycin, suggesting that chrysanthemum volatile oil might play a role in suppressing mutation formation. A research has also indicated that the compound extracted from the chrysanthemum has a strong anti-bacterial activity - They have shown that at low concentrations, its antibacterial activity is gradually elevated with increasing concentrations of the extract, although the elevation is obvious at high concentrations. Further chemical analysis has revealed that the main components of the volatile oil include lemon oil, $\beta$-golden hepenene and oxidized hexapenene .

Volatile oil extracted from "Hang Ju" could significantly inhibit the swelling of the ear shell caused by xyleneinduced inflammation in mice (39). Meanwhile, it could also inhibit the swelling of rats' feet caused by carrageenan-induced inflammation in a short period of time, and the level of prostaglandin E2 in the inflammatory model is significantly reduced, indicating that volatile oil may play an anti-inflammatory role by inhibiting the production of inflammatory factors. It would be quite interesting to note that an investigation has indicated that chrysanthemum volatile oil could significantly reduce the body temperature of fevered rats instead of the non-volatile oil (40). In addition, another research has revealed that low, medium and high doses of volatile oil extracted from "Hang Ju" are able to significantly reduce the elevated body temperature caused by endotoxin in rabbits in a dose-dependent manner. This study further suggests that the fever relieving mechanism may be related to changes in the content of monoamine neurotransmitters including norepinephrine, dopamine, and 5-hydroxytryptamine in the hypothalamus tissue due to the volatile oil intake (41).

Another study suggests that pyrethroids in the chrysanthemum volatile oil could be the active ingredient that possesses a significant cytotoxic effect on human nasopharyngeal cancer cell strain CNE1 by inducing in time- and dose-dependent manners.

\section{Organic acids in chrysanthemum extracts and their potential pharmacological effects}

\subsection{Types of organic acids}

Chlorogenic acid (also named 3-O-caffeoylquinic acid and caffetannic acid) and its derivatives are the main organic acid compounds discovered in chrysanthemum extracts. As a phenolic acid compound, the chlorogenic acid is made up of the coffee acid and quinine acid. Therefore, the derivatives of chlorogenic acid include caffeoylquinic acids, dicaffeoylquinic acids, and caffeoylquinic acid esters $(42,43)$. 
Table 1. General categories of the currently reported main components from chrysanthemum and their potential pharmacological effects.

\begin{tabular}{c|l|l}
\hline Components & \multicolumn{1}{c|}{ Types } & \multicolumn{1}{c}{ Pharmacological effects } \\
\hline Flavonoids & $\begin{array}{l}\text { Mainly flavonoids (apigenin, luteolin, quercetin, etc.) and their } \\
\text { derivatives } \\
\text { Monoterpenes, sesquiterpenes, their oxygen-containing } \\
\text { derivatives, aromatic compounds, and alkanes } \\
\text { Caffetannic acid, quinine acid and the derivatives of } \\
\text { bloctial, anti-cancer, and anti-HIV }\end{array}$ & $\begin{array}{l}\text { Mutation suppression, anti-inflammation, } \\
\text { and anti-cancer }\end{array}$ \\
Organic acids & $\begin{array}{l}\text { Polysaccharides composed of galactose, glucose, arabinose, } \\
\text { rhamnose, mannitose, xylose, and ribose }\end{array}$ & $\begin{array}{l}\text { Anti-oxidant, anti-tumor, immune- } \\
\text { modulation, and blood sugar reduction } \\
\text { regulation }\end{array}$ \\
Others & $\begin{array}{l}\text { Vitamin C and metal elements } \\
\text { Reduce the levels of lead in both bone and } \\
\text { blood tissues }\end{array}$ \\
\hline
\end{tabular}

\subsection{Pharmacological effects of organic acids}

Pharmacological effects of anti-oxidant, anti-tumor, immunomodulation and blood sugar reduction have been suggested to be linked with chlorogenic acid and derivatives extracted from chrysanthemum (44).

Investigations have revealed that organic acids extracted from chrysanthemum possess a wide range of anti-oxidant activities, since the chlorogenic acid and derivatives show strong inhibition and removal effect on free radicals such as 2,2-diphenyl-1-picrylhydrazyl (DPPH), lipid oxidation derivatives and hyperoxides. In addition, reducibility of these organic acids on oxidized iron even surpasses vitamin C (45). This is due to the reductive hydroxyl group in the chlorogenic acid molecule, which forms a proton with anti-oxidative ability. When combined with free radicals such as hydroxyls or super-oxygen anions, the deionized proton could stabilize these free radicals and hence protect cells and tissues from oxidation.

In a study conducted on primary cells separated from the Lewis lung cancer mouse and in human lung cancer cells A549, chlorogenic acid has been found to maintain a certain level of inhibitory effect in vitro and in vivo, with the peak inhibitory dose at $20 \mathrm{mg} / \mathrm{kg}$ (46). It is speculated that the inhibitory effects on these lung cancers is achieved both directly by inducing apoptosis in cancerous cells and indirectly by regulating immune surveillance $\mathrm{T}$ cells. In addition, chlorogenic acid has a significant inhibitory effect on CT26 colon cancer transplanted tumors (47), where the tumor suppression rate increases with elevated concentrations of chlorogenic acid.

The regulatory role of chlorogenic acid and derivatives from chrysanthemum on immune system is also quite obvious in some investigations. Chlorogenic acid could significantly upregulate the levels of INF- $\gamma$ and tumor necrosis factor (TNF)- $\alpha$ in both epithelial lymphocytes and inherent lymphocytes in the intestine, and high doses of chlorogenic acid could also promote the secretion of TNF- $\alpha$ in peripheral monocytes in the blood. In addition, studies have shown that chlorogenic acid can promote the productions of INF- $\gamma$ and TNF- $\alpha$ in human lymphocytes and peripheral white blood cells, and enhance the proliferation of $\mathrm{T}$ cells caused by influenza virus antigens.

Chlorogenic acid has also been found to effectively reduce the blood sugar levels in an alloxan-treated diabetic mouse model, and there is no significant difference in blood glucose values among the high-, medium- and lowdose groups after administration. However, it has no significant effect on blood sugar levels in normal mice, suggesting it might be directly related with the alloxan induced signaling. Another report suggests that 1,5-bisO-caffeoylquinic acid, a derivative of chlorogenic acid, could reduce the occurrence of hepatic damage including fibrosis, and hence possesses a protective role in liver cells. The molecular mechanism remains unclear, but the investigation suggests this compound could inhibit the proliferation cycle of damaged liver cells, promote normal cell vitality, and regulate the levels of glutamicpyruvic transaminase and glutamic-oxaloacetic transaminase in the serum, thereby protecting against the pathological structural changes due to acute damage.

\section{Polysaccharides in chrysanthemum extracts and their potential pharmacological effects 5.1 Types of polysaccharides}

Polysaccharides are complicated and macro molecules composed of dehydrated and condensed mono-saccharides. At present, the research on the chemical structure of polysaccharides in chrysanthemum extracts has mainly focused on the composition and connection of monosaccharides by determining their biological activities. Current understanding shows that polysaccharides from chrysanthemum are mainly composed of galactose, glucose, arabinose, rhamnose, mannitose, xylose and ribose. Among these mono-saccharides, galactose and glucose are the most abundant ones (48).

\subsection{Pharmacological effects of polysaccharides}

Evidence also indicates that polysaccharides from chrysanthemum extracts possess pharmacological functions including anti-oxidant, anti-tumor and immune regulation.

In vitro experiments showed that three types of 
Table 2. Flavonoids in Chrysanthemum extract and their potential pharmacological effects.

\begin{tabular}{|c|c|c|c|}
\hline Components & Chemical Name & Molecular Formula & Pharmacological effects \\
\hline $\begin{array}{l}\text { Total flavonoids of } \\
\text { Chrysanthemum }\end{array}$ & Mixture & Mixture & $\begin{array}{l}\text { 1. Antioxidant } \\
\text { 2. Blood lipid reduction }\end{array}$ \\
\hline $\begin{array}{l}\text { Wild Chrysanthemum total } \\
\text { flavonoids }\end{array}$ & Mixture & Mixture & Anti-microbial \\
\hline Quercetin & $3,5,7,3^{\prime}, 4^{\prime}$-Pentahydroxyflavone & $\mathrm{C}_{15} \mathrm{H}_{10} \mathrm{O}_{7}$ & $\begin{array}{l}\text { 1. Inhibit the proliferation of tumor cells } \\
\text { 2. The injury of lipid peroxidation }\end{array}$ \\
\hline Luteolin & 3',4',5,7-Tetrahydroxyflavone & $\mathrm{C}_{15} \mathrm{H}_{10} \mathrm{O}_{6}$ & $\begin{array}{l}\text { 1. Inhibit the metastasis of ovarian cancer } \\
\text { cells } \\
\text { 2. Anti-inflammatory } \\
\text { 3. Improve the airway remodeling in } \\
\text { asthma model mice }\end{array}$ \\
\hline Luteolin-7-O- $\beta-\mathrm{D}-$ glucosin & $\begin{array}{l}\text { b-D-Glucopyranosiduronic acid,2- } \\
\text { (3,4-dihydroxyphenyl)-5-hydroxy- } \\
\text { 4-oxo-4H-1-benzopyran-7-yl }\end{array}$ & $\mathrm{C}_{21} \mathrm{H}_{20} \mathrm{O}_{11}$ & Anti-inflammatory \\
\hline Apigenin-7-O- $\beta$-D-glucosin & $\begin{array}{l}\text { b-D-Glucopyranosiduronic acid,5- } \\
\text { hydroxy-2-(4-hydroxyphenyl)-4- } \\
\text { oxo-4H-1-benzopyran-7-yl }\end{array}$ & $\mathrm{C}_{21} \mathrm{H}_{20} \mathrm{O}_{10}$ & Anti-inflammatoryanti-hypertensive \\
\hline $\begin{array}{l}\text { Apigenin-7-O- } \beta \text {-D- } \\
\text { (4"-caffeoyl)- glucuronide }\end{array}$ & & $\mathrm{C}_{30} \mathrm{H}_{24} \mathrm{O}_{14}$ & Anti-HIV \\
\hline Linarin & $\begin{array}{l}\text { 7-[[6-O-(6-deoxy-alpha-L- } \\
\text { mannopyranosyl)-beta-D- } \\
\text { glucopyranosyl]oxy]-5-hydroxy-4'- } \\
\text { methoxyflavone }\end{array}$ & $\mathrm{C}_{28} \mathrm{H}_{32} \mathrm{O}_{14}$ & Anti-inflammatory \\
\hline
\end{tabular}

polysaccharides from chrysanthemum (with different molecular weights ranging from $<100 \mathrm{kDa}, 100-300$ $\mathrm{kDa}$ and $>300 \mathrm{kDa}$, respectively) all possess reducibility on radicals such as DPPH, hydroxyl free radicals and hyperoxide anion, indicating that these polysaccharides are able to remove free radicals and serve as anti-oxidant. Another in vivo study also demonstrates that these polysaccharides have potent anti-oxidative activity (49). However, after refining the polysaccharides, their free radical removal activity is reduced in the fine product, suggesting that some substances such as binding proteins might have synergistic effects on the anti-oxidative activity of polysaccharides from chrysanthemum.

Additional investigations have shown that the aforementioned three types of polysaccharides with different molecular weights have a significant inhibitory effect on human liver cancer cell line HepG-2 in a dosedependent manner (50). The polysaccharide with medium molecular weight could also reduce the proliferation of human breast cancer cell line MCF-7 (51). Another research demonstrates that six kinds of polysaccharides isolated from chrysanthemum extracts can reduce the survival rate of the human pancreatic cancer cell line PANC-1, but do not affect or even enhance the human normal liver cell line L02, suggesting these polysaccharides can be served as a potential anti-cancer drug due to their safety.

Apart from the aforementioned organic acid components, chrysanthemum polysaccharides could significantly raise the levels of INF- $\gamma$ and TNF- $\alpha$ in peripheral white blood cells as well. Study in cyclophosphamide-treated mice with a low immune function has shown that chrysanthemum polysaccharides in high and low-dose groups could both significantly increase the intensity of delayed allergy, increase the serum hemolytic level, and promote the production of hemolysin antibodies in these mice, indicating that chrysanthemum polysaccharides improve cellular and humoral immunities in immunesuppressive mice.

\section{Others}

Abundant vitamin $\mathrm{C}$ and metal elements have been uncovered in chrysanthemum extracts as well (52). Study has shown that the levels of lead in both bone and blood tissues is reduced in lead poisoned mice after application of chrysanthemum tea. Moreover, the amounts of hemoglobin and red blood cells are significantly higher in treated mice compared with the model group. This phenomenon could be attributed to a low solubility of ascorbic lead salt which is formed by combining vitamin $\mathrm{C}$ with the lead ion. In addition, another study suggests that vitamin $\mathrm{C}$ could accelerate the metabolism of lead thus preventing its deposition. Moreover, selenium in chrysanthemum together with some binding proteins could also be combined with lead to form stable chelates, which aids lead excretion. Meanwhile, iron, zinc and 
Table 3. Pharmacological effects of essential oils from different chrysanthemum species.

\begin{tabular}{|c|c|c|}
\hline \multicolumn{2}{|c|}{ Components } & Pharmacological effects \\
\hline \multicolumn{2}{|c|}{ Volatile Oils from the Flowers of Chamomile } & $\begin{array}{l}\text { Inhibit sister-strand crossover induced by erythromycin, } \\
\text { Methylene sulfonate in mouse bone marrow }\end{array}$ \\
\hline \multirow{3}{*}{$\begin{array}{l}\text { Volatile Oils from the Flowers of } \\
\text { Chrysanthemum nankingense }\end{array}$} & Lemon oil & \multirow{3}{*}{ Anti-bacterial activity } \\
\hline & $\beta$-golden hepenene & \\
\hline & Oxidized hexapenene & \\
\hline \multicolumn{2}{|c|}{ Volatile oil extracted from "Hang Ju" } & $\begin{array}{l}\text { 1. Inhibit the swelling of the ear shell induced by } \\
\text { inflammation } \\
\text { 2. Reduce the body temperature rise caused by endotoxin }\end{array}$ \\
\hline \multicolumn{2}{|c|}{ Pyrethroids } & $\begin{array}{l}\text { Possess a significant cytotoxic effect on human } \\
\text { nasopharyngeal cancer cell strain CNEl }\end{array}$ \\
\hline
\end{tabular}

calcium in chrysanthemum extracts could also antagonize the absorption of lead.

\section{Conclusion and prospects}

The composition and pharmacological effects of chrysanthemum extracts have been studied extensively in China, which has been briefly translated and summarized in this mini review. However, more investigations on several directions are urgently needed before a broader range of medicinal applications of chrysanthemum and its components. Firstly, many investigations have focused mainly on the pharmacological effects of chrysanthemum extract. However, not much is known about the potential toxicity in terms of dose, origin and processing method of chrysanthemum, which could be quite important for the safety issues of its application. Secondly, although many investigations have demonstrated some molecular mechanisms underlying the pharmacological effects, most of them lack the specific upstream molecular targets that are affected directly. Thus, limited information on sensitivity and specificity hinders further development of these components to potential drugs. Last but not least, due to different origins and processing methods of chrysanthemum, the compositions may vary, which also pose as obstacles on the way to the commercial utilization of chrysanthemum. Therefore, a strict criterion based on more detailed analytical and pharmacological investigations is highly warranted for chrysanthemum and its extracts.

\section{References}

1. Ohmiya A. Molecular mechanisms underlying the diverse array of petal colors in chrysanthemum flowers. Breed Sci. 2018;68(1):119-27.

2. Teixeira da Silva JA. Chrysanthemum: advances in tissue culture, cryopreservation, postharvest technology, genetics and transgenic biotechnology. Biotechnol Adv. 2003;21(8):715-66.

3. Su J, Jiang J, Zhang F, Liu Y, Ding L, Chen S, et al. Current achievements and future prospects in the genetic breeding of chrysanthemum: a review. Hortic Res. 2019;6:109.

4. He J, Chen L, Chu B, Zhang C. Determination of total polysaccharides and total flavonoids in chrysanthemum morifolium using near-infrared hyperspectral imaging and multivariate analysis. Molecules. 2018;23(9).
5. Li Y, Yang P, Luo Y, Gao B, Sun J, Lu W, et al. Chemical compositions of chrysanthemum teas and their antiinflammatory and antioxidant properties. Food Chem. 2019;286:8-16.

6. Wang $Y, X u Z$, Wen X, Li M, Pang S, Huang $Y$, et al. The formation and bioactivities of green substances in Chrysanthemum morifolium tea. Food Chem. 2019;286:268-74.

7. Yang L, Aobulikasimu.Nuerbiye, Cheng P, Wang JH, Li $H$. Analysis of floral volatile components and antioxidant activity of different varieties of chrysanthemum morifolium. Molecules. 2017;22(10).

8. Zhu ZY, Pan LC, Yun T, Zhang YM. Structural analysis and antioxidant activity of the glycoside from Imperial Chrysanthemum. Bioorg Med Chem Lett. 2018;28(9):1581-90.

9. Wang C. [Advances in the study on chemical constituents of Chrysanthemum morifolium Ramat]. Zhong Yao Cai. 2004;27(3):224-6.

10. Kim IS, Koppula S, Park PJ, Kim EH, Kim CG, Choi WS, et al. Chrysanthemum morifolium Ramat (CM) extract protects human neuroblastoma SH-SY5Y cells against MPP+-induced cytotoxicity. J Ethnopharmacol. 2009;126(3):447-54.

11. Lin GH, Lin L, Liang HW, Ma X, Wang JY, Wu LP, et al. Antioxidant action of a Chrysanthemum morifolium extract protects rat brain against ischemia and reperfusion injury. J Med Food. 2010;13(2):306-11.

12. Zheng $\mathrm{CH}$, Zhang $\mathrm{M}$, Chen $\mathrm{H}$, Wang $\mathrm{CQ}$, Zhang $\mathrm{MM}$, Jiang $\mathrm{JH}$, et al. Luteolin from Flos Chrysanthemi and its derivatives: New small molecule Bcl-2 protein inhibitors. Bioorg Med Chem Lett. 2014;24(19):4672-7.

13. Yang C, Chen H, Lu S, Zhang M, Tian W, Wang M, et al. Structural modification of Iuteolin from Flos Chrysanthemi leads to increased tumor cell growth inhibitory activity. Bioorg Med Chem Lett. 2016;26(15):3464-7.

14. Yang HM, Sun CY, Liang JL, Xu LQ, Zhang ZB, Luo $D D$, et al.Supercritical-carbon dioxide fluid extract from chrysanthemum indicum enhances anti-tumor effect and Reduces Toxicity of Bleomycin in Tumor-Bearing Mice. Int J Mol Sci. 2017;18(3).

15. Wang $\mathrm{T}$, Jiang $\mathrm{H}$, Ji $\mathrm{Y}, \mathrm{Xu}$ J. [Anti-oxidation effect of water extract of Flos chrysanthemi on heart and brain in vivo and in vitro]. Zhong Yao Cai. 2001;24(2):122-4.

16. He Y, Du Z, Lv H, Jia Q, Tang Z, Zheng X, et al. Green synthesis of silver nanoparticles by Chrysanthemum morifolium Ramat. extract and their application in clinical ultrasound gel. Int J Nanomedicine. 2013;8:1809-15.

17. Arokiyaraj S, Arasu MV, Vincent S, Prakash NU, Choi SH, Oh YK, et al. Rapid green synthesis of silver nanoparticles from Chrysanthemum indicum $L$ and its antibacterial and cytotoxic effects: an in vitro study. Int $\mathrm{J}$ Nanomedicine. 2014;9:379-88.

18. Tao JH, Duan JA, Qian YY, Qian DW, Guo JM. Investigation 
of the interactions between Chrysanthemum morifolium flowers extract and intestinal bacteria from human and rat. Biomed Chromatogr. 2016;30(11):1807-19.

19. Lin L, Mao X, Sun Y, Rajivgandhi G, Cui H. Antibacterial properties of nanofibers containing chrysanthemum essential oil and their application as beef packaging. Int $J$ Food Microbiol. 2019;292:21-30.

20. Cui Y, Wang X, Xue J, Liu J, Xie M. Chrysanthemum morifolium extract attenuates high-fat milk-induced fatty liver through peroxisome proliferator-activated receptor alphamediated mechanism in mice. Nutr Res. 2014;34(3):268-75.

21. Tsai PJ, Chang ML, Hsin CM, Chuang CC, Chuang LT, Wu WH. Antilipotoxicity Activity of Osmanthus fragrans and Chrysanthemum morifolium Flower Extracts in Hepatocytes and Renal Glomerular Mesangial Cells. Mediators Inflamm. 2017;2017:4856095.

22. Cha JY, Nepali S, Lee HY, Hwang SW, Choi SY, Yeon JM, et al. Chrysanthemum indicum L. ethanol extract reduces high-fat diet-induced obesity in mice. Exp Ther Med. 2018;15(6):5070-6.

23. Xu WB, Guo QS, Li YN, Wang T. [Comparative study on internal quality of various Chrysanthemum morifolium]. Zhongguo Zhong Yao Za Zhi. 2005;30(21):1645-8.

24. Xie YY, Qu JL, Wang QL, Wang Y, Yoshikawa M, Yuan D. Comparative evaluation of cultivars of Chrysanthemum morifolium flowers by HPLC-DAD-ESI/MS analysis and antiallergic assay. J Agric Food Chem. 2012;60(51):12574-83.

25. Xia DZ, Lv GY, Yu XF, Wang HM, Yang Q. [Antagonism of total flavonoids from Chrysanthemum morifolium against lead induced oxidative injury in mice]. Zhongguo Zhong Yao Za Zhi. 2008;33(23):2803-8.

26. Zhang J, Zhang L, Li J, Cheng W, Peng L, Zhang Q. [Effects of total flavonoids of Chrysanthemum indicum on free radical in adjuvant arthritic rats]. Zhongguo Zhong Yao Za Zhi. 2010;35(3):344-7.

27. Li G, Zhang H, Li Y, Wang Y. [Protection of vascular endothelial cells from high glucose injury induced by quercetin]. Zhong Yao Cai. 2002;25(4):268-70.

28. Shahzad H, Giribabu N, Sekaran M, Salleh N. Quercetin Induces Dose-Dependent Differential Morphological and Proliferative Changes in Rat Uteri in the Presence and in the Absence of Estrogen. J Med Food. 2015;18(12):1307-16.

29. Liu YH, Mou X, Zhou DY, Zhou DY, Shou CM. Extraction of flavonoids from Chrysanthemum morifolium and antitumor activity in vitro. Exp Ther Med. 2018;15(2):1203-10.

30. Huang CS, Lii CK, Lin AH, Yeh YW, Yao HT, Li CC, et al. Protection by chrysin, apigenin, and luteolin against oxidative stress is mediated by the Nrf2-dependent up-regulation of heme oxygenase 1 and glutamate cysteine ligase in rat primary hepatocytes. Arch Toxicol. 2013;87(1):167-78.

31. Wang H, Luo Y, Qiao T, Wu Z, Huang Z. Luteolin sensitizes the antitumor effect of cisplatin in drug-resistant ovarian cancer via induction of apoptosis and inhibition of cell migration and invasion. J Ovarian Res. 2018;11(1):93.

32. Aziz N, Kim MY, Cho JY. Anti-inflammatory effects of luteolin: A review of in vitro, in vivo, and in silico studies. $J$ Ethnopharmacol. 2018;225:342-58.

33. Kim JS, Jobin C. The flavonoid luteolin prevents lipopolysaccharide-induced NF-kappaB signalling and gene expression by blocking IkappaB kinase activity in intestinal epithelial cells and bone-marrow derived dendritic cells. Immunology. 2005;115(3):375-87.

34. Jang TY, Jung AY, Kyung TS, Kim DY, Hwang JH, Kim YH Anti-allergic effect of luteolin in mice with allergic asthma and rhinitis. Cent Eur J Immunol. 2017;42(1):24-9.

35. Hu CQ, Chen K, Shi Q, Kilkuskie RE, Cheng YC, Lee KH. Anti-AIDS agents, 10. Acacetin-7-O-betaD-galactopyranoside, an anti-HIV principle from
Chrysanthemum morifolium and a structure-activity correlation with some related flavonoids. J Nat Prod. 1994;57(1):42-51.

36. Lee JS, Kim HJ, Lee YS. A new anti-HIV flavonoid glucuronide from Chrysanthemum morifolium. Planta Med. 2003;69(9):859-61.

37. Chen X, Tan X, Tanaka K, Bi K. [Study of the chemical components of volatile oil from Flos chrysanthemum indici by gas chromatography-mass spectrometry]. Se Pu. 2005;23(2):213.

38. Hassanpouraghdam MB. Flowerhead volatile oil composition of soilless culture-grown Chrysanthemum balsamita L. Nat Prod Res. 2009;23(7):672-7.

39. Yao W, Zhang L, Hua Y, Ji P, Li P, Li J, et al. The investigation of anti-inflammatory activity of volatile oil of Angelica sinensis by plasma metabolomics approach. Int Immunopharmacol. 2015;29(2):269-77.

40. Ashour MM, Tahir KEHE, Morsi MG, Aba-Alkhail NAJNPE Effect of the volatile oil of Nigella sativa seeds and its components on body temperature of mice: elucidation of the mechanisms of action. Nat Prod Sci. 2006;12(1):14-8.

41. Plaingam W, Sangsuthum S, Angkhasirisap W, Tencomnao T. Kaempferia parviflora rhizome extract and Myristica fragrans volatile oil increase the levels of monoamine neurotransmitters and impact the proteomic profiles in the rat hippocampus: Mechanistic insights into their neuroprotective effects. J Tradit Complement Med. 2017;7(4):538-52.

42. Clifford MN, Wu W, Kirkpatrick J, Kuhnert N. Profiling the chlorogenic acids and other caffeic acid derivatives of herbal chrysanthemum by LC-MSn. J Agric Food Chem. 2007;55(3):929-36.

43. Tsevegsuren N, Fujimoto K, Christie WW, Endo Y. Occurrence of a novel cis,cis,cis-octadeca-3,9,12-trienoic (Z,Z,Z-octadeca-3,9,12-trienoic) acid in Chrysanthemum (tanacetum) zawadskii herb. (Compositae) seed oil. Lipids. 2003;38(5):573-8

44. Li Z, Chen Z, Liao L, Lin S. [Determination of chlorogenic acid in chrysanthemum morifolium Ramat.flower]. Zhongguo Zhong Yao Za Zhi. 1999;24(6):329-30, 81.

45. Hwang SJ, Kim YW, Park Y, Lee HJ, Kim KW Anti-inflammatory effects of chlorogenic acid in lipopolysaccharide-stimulated RAW 264.7 cells. Inflamm Res. 2014;63(1):81-90.

46. Yamagata K, Izawa Y, Onodera D, Tagami M. Chlorogenic acid regulates apoptosis and stem cell marker-related gene expression in A549 human lung cancer cells. Mol Cell Biochem. 2018;441(1-2):9-19.

47. Xie YY, Yuan D, Yang JY, Wang LH, Wu CF. Cytotoxic activity of flavonoids from the flowers of Chrysanthemum morifolium on human colon cancer Colon205 cells. J Asian Nat Prod Res. 2009;11(9):771-8.

48. Zheng $\mathrm{Y}$, Wang XS, Fang J. Two acidic polysaccharides from the flowers of Chrysanthemum morifolium. J Asian Nat Prod Res. 2006;8(3):217-22.

49. Du N, Tian W, Zheng D, Zhang X, Qin P. Extraction, purification and elicitor activities of polysaccharides from Chrysanthemum indicum. Int J Biol Macromol. 2016;82:347-54.

50. Chai Y, Wang G, Fan L, Zhao M. A proteomic analysis of mushroom polysaccharide-treated HepG2 cells. Sci Rep. 2016;6:23565

51. Yang L, Wei DD, Chen Z, Wang JS, Kong LY. Reversal of multidrug resistance in human breast cancer cells by Curcuma wenyujin and Chrysanthemum indicum. Phytomedicine. 2011;18(8-9):710-8.

52. Cheng $\mathrm{H}, \mathrm{Cao} \mathrm{Y}$. [Determination of hydroxyl radical in CuSO4-vitamin $\mathrm{C}$ reaction system and scavenging activities of Chrysanthemum using capillary electrophoresis with electrochemical detection]. Se Pu. 2007;25(5):681-5. 